\title{
Antonymous Adjectives in Disyllabic Lexical Compounds in Mandarin: A Cognitive Linguistics Perspective
}

\author{
Yuan Zhang ${ }^{1, *}$, Suzanne Kemmer ${ }^{2}$ \\ ${ }^{1}$ School of Foreign Languages, Shandong Normal University, China \\ ${ }^{2}$ Department of Linguistics, Rice University, Houston, USA
}

Copyright $(\subset 2015$ by authors, all rights reserved. Authors agree that this article remains permanently open access under the terms of the Creative Commons Attribution License 4.0 International License

\begin{abstract}
Corpus-based research into antonyms in English, Sweden and Japanese has gradually brought the lexical relation of antonymy into functional-cognitive linguistics in recent years. When antonymous adjectives are examined in Mandarin corpora, we find that they co-occur in both discontinuous constructions, for example, 既不热也不 冷 ji bure ye buleng, literally not hot also not cold, 'neither hot nor cold', and lexical compounds, often called disyllabic compounds, for example, 大小 da xiao, literally big-small, 'size'. This study is a cognitive account of Mandarin disyllabic compound constructions composed of two antonymous adjective roots, such as 长短 chang duan, literally long-short, 'length', 左右 zuo you, literally left-right, 'control', and 反正 fan zheng, literally back-face, 'anyway'. With the help of the Lancaster corpus of Mandarin Chinese (LCMC) and the corpus from the Center for Chinese Linguistics (CCL), 51 instances of antonymous adjective compounds were retrieved. When the antonymous adjectives co-occur, there are interactions between the componential semantics and the constructional semantics. While the disyllabic compound constructions may inherit the part of speech from their components, they may also have their own part of speech, functioning as nouns, adverbs and even verbs. The different categories reflect different construals of the same conceptual content. In a nutshell, by adopting a cognitive linguistics approach, we show that the different uses of these compounds are related in a systematic way.
\end{abstract}

Keywords Antonymous Adjectives, Disyllabic Lexical Compounds, Cognitive Linguistics

\section{Introduction}

Antonymy is traditionally regarded as a paradigmatic relation. However, the members of a antonym pair also present relatively higher co-occurrence tendency than synonyms and hyponyms (e.g. Justeson \& Katz [17]; Mettinger [22]; Fellbaum [8]; Willners [36]). Antonymy is thus proposed to be a syntagmatic relation, which usually occur in contrastive constructions (Fellbaum [8]; Jones [14]; Murphy [24]). Recent years have seen a rise of interests in the functional-cognitive aspect of the co-occurrence of antonyms in constructions. Jones [14] make a categorization of antonymy functions in the corpus of English newspaper, followed by its applications in English adult speech (Jones [15]), English child speech and child-directed speech (Jones \& Murphy [16]; Murphy \& Jones [29]), as well as other languages, such as Swedish (e.g. Murphy et al [28]) and Japanese (Muehleisen \& Isono [24]). Almost the same discourse functions of antonyms have been found in different languages, but the usage frequencies are different which may be ascribed to cultural factors.

Antonymous adjectives constitute a large portion of the data in corpora in previous studies, $60 \%$ in Jones's study and $82 \%$ in Murphy et al.'s. Adjectives are characterized by gradability. Gradable opposites are considered as the most "prototypical" type of opposites (e.g. Lyons [21]; Cruse [2]; Murphy [25]; Muehleisen \& Isono [24]). The high frequency of their co-occurrence is proposed to be related to the greater shared collocational range between the members than that between near opposites (Muehleisen [23]; Willners [36]). Besides, the co-occurrence of antonymous adjectives has its psychological plausibility. Having investigated thirty-four pairs of adjectives that had a reciprocal property in a list of 278 most frequent adjectives, Deese [4] found that at least the most frequent antonymous adjectives are associated with each other more directly than with other adjectives. Charles and Miller [1] contrasted two accounts for lexical association-substitutability hypothesis and co-occurrence hypothesis, concluding that the associative pairing of antonymous adjectives should be ascribed to the sentential co-occurrence alone. Justeson and Katz [17] extended Charles and Miller's study. They argued that the co-occurrence takes place by substitution which yields the antonym alignment, and the alignment makes the association possible. These psychological tests all point to one conclusion that the members of antonymous adjectives are more closely connected in our minds so that they tend to 
prime each other.

When antonymous adjectives are examined in Mandarin corpora, the co-occurrence is also popular. For example,

(1). 这个地方既不热也不冷。

Zhe ge (Cl.) difang ji bure ye buleng

This $\mathrm{Cl}$. place neither hot nor cold

It is neither hot nor cold here.

(2). 在巴黎, 无论大街小巷, 随处可见一张张独 脚的小圆桌。

Zai bali, wulun dajie xiaoxiang, suichu kejian yi zhangzhang $(\mathrm{Cl}$.) dujiaode xiaoyuanzhuo.

In Praris, no matter big street small lane, everywhere may see one after another single-legged round table

One after another single-legged round tables are distributed in both streets and lanes in Paris.

In Murphy's [24] term, these are called discontinuous constructions. However, what is more particular of Mandarin is that antonymous adjectives also co-occur in disyllabic lexical compounds (Huang, 1998; Wang, 2010). For example,

(3). 冰岛的温泉特别多, 大小温泉有 200 多个。

Bingdao de wenquan tebie duo, daxiao wenquan you 200 duo ge

Ice island's warm spring especially many, big small warm spring have 200 more $\mathrm{Cl}$.

There are very many warm springs on the ice island, totally more than 200 including big and small ones.

(4). 高低收入之间的差距依然略有所拉大。

Gaodi shouru zhijian de chaju yiran lue yousuo lada

High low income between gap still a little widen

The gap between high and low incomes has still widened.

Literature review shows that antonymous adjectives in discontinuous constructions have been focused on a lot, but little research concerns their co-occurrence in lexical compounds. Besides, the current research is mostly descriptive without sufficient cognitive explanation. This study is a cognitive account of Mandarin disyllabic compound constructions composed of two antonymous adjective roots, such as 长短 chang duan, literally long-short, 'length', 左右 zuo you, literally left-right, 'control', and 反 IE fan zheng, literally back-face, 'anyway'. Different syntactic functions and semantics of compounds, as well as the componential features of compounds are worthy of being accounted for.

The perspective of cognitive grammar being taken, this paper proposes that the component adjectives have their own characteristics which provide part of predictability for their co-occurrence in constructions. The semantics of the constructions always involve the scales evoked by the antonymous adjectives. The extension of the semantics mainly depends on the cognitive mechanism of metonymy. When different construal perspectives on the conceptual content of the construction are taken, grammatical categories of the construction also change.

The organization of the paper is as follows. Section 2 provides a theoretical background of cognitive grammar. Section 3 introduces how the data are extracted. Section 4 gives a panorama of antonymous adjectives, mainly focusing on the semantic properties of componential adjectives, the ordering of adjectives in compounds, semantics and syntactic functions of compounds. Section 5 explores the cognitive nature of the relative aspects of this linguistic phenomenon to support the core proposal. Section 6 discusses the conventionalization and cultural factors that may contribute to this phenomenon. Section 7 concludes.

\section{Theoretical Background}

\subsection{Why Choose the Perspective of Cognitive Grammar?}

Cognitive grammar (CG) stands out with several basic tenets setting the conceptual foundation of this linguistic phenomenon. First, there is no clear-cut boundary between linguistic and non-linguistic factors; second, grammar is meaningful and can be described conceptually; third, human take certain perspectives to construe the physical world (Langacker [18][19]).

Within the cause of cognitive linguistics, CG acknowledges human language as an integral part of cognition. Linguistic structure cannot be understood without drawing on basic human mental abilities, like focusing and shifting attention, forming and manipulating images, establishing correspondences, inference, conceptualizing and so on. However, CG does not deny the grounding of language in interaction and the fact that language is not a self-contained entity in our minds. Language structures are functionally motivated and cannot be separated from such non-linguistic factors as the encyclopedic knowledge and our bodily experiences. Therefore, CG has its functional nature; meanwhile it commits itself to a fine-grained description of language structures.

Contrary to the idea of the autonomy of grammar, CG strongly resides grammar in the symbolization and conceptualization. Grammar is symbolic by semantic and phonological poles. Novel expressions can be generated on fixed ones, which exhibit higher symbolic complexities. So lexicon and grammar form a continuum. Grammar cannot be featured without resorting to semantic aspects. That is why conceptualization is always involved in describing grammar in CG. Conceptualization, profiling the dynamic processing in the mind, helps to structure established conceptions, generate new conceptions, and combine the various contexts like physical, linguistic, social and cultural.

In $\mathrm{CG}$, the semantics of an expression are not only 
understood by its conceptual content. It lies in how we construe the conceptual content of an expression. The conceptual content can always be related to a certain scene, concretely or metaphorically. The location where we stand, the distance between us and the scene, and the focused facet of the scene may affect how we structure the conceptual elements of the scene, hence how to structure the linguistic elements of the expression. This echoes with the second position that grammar is meaningful, and the meaning lies in the conceptualization which is functionally motivated.

The Mandarin linguistics phenomenon of antonymous adjectives co-occurring in disyllabic compounds is a lexical as well as grammatical phenomenon. The structure of the compounds reflects the conceptual content evoked by the compounds. The semantic and functional motivations are to be explored based on detailed and conceptual descriptions of the construction.

\subsection{Grammatical Categories from the View of Cognitive Grammar}

Nouns, verbs, adjectives, and adverbs are categories established for the facet of grammar. Grammatical categories are usually defined in terms of their grammatical behavior. In CG, they have semantic properties, which lie in collection of notions that are "prevalent in characterizing their grammatical behavior and contributing to the semantic cohesiveness of construction-based classes" across languages (Langacker [19]: 97). The conceptions with the highest cognitive salience usually induce a grammatical category. In the process of the emergence of a category, the basic cognitive ability must be involved, which has been ignored by the traditional framework. Then what determines the grammatical category of an expression? This is relevant to an expression's meaning. As discussed above, how we apprehend an expression depends on how we conceptualize the scene evoked by the expression instead of the overall conceptual content. Therefore, in CG, the profile of the conceptual content plays a determining role in the grammatical categorization. The same expression, sharing the same conceptual foundation and with different profiles, can be categorized differently. Any clear-cut boundary among the categories seems to be arbitrary. Antonymous adjectives co-occurring in disyllabic compounds may be set in various constructions and certain aspects of their conceptual contents profile correspondingly, thus function as different grammatical categories.

\subsection{Constructions from the View of Cognitive Grammar}

Symbolic structures, the pairing of semantic poles and phonological poles, can be combined together to form more elaborate structures which are also symbolic in nature. Constructions consist of such symbolic assemblies including component structures and composite structures. The relations of symbolization, integration and composition are basics of constructions in CG (Langacker [19]). The analysis of any construction depends on the detailed description of component and composite structures, as well of their relations.

The compositionality is one of basic ways for human beings to create new expressions. We can abstract from the reoccurring expressions the patterns of symbolic structures, which in turn serve a template for new expressions. The abstracted schema is called the constructional schema in CG. Even though composite structure elements inherit from component structure elements, composite structures have their own emergent properties. Component structures provide a way of understanding composite structures. The correspondence between component structures and that between component structures and composite structures are not simply a relation of summation. There may be a discrepancy between the expected and the actual meanings of an expression. It is due to the fact that the component structures and the constructional schemas just serve part in understanding or generating new expressions. Besides, the encyclopedic knowledge, the context and the mental abilities like metaphor, metonymy, blending also contribute. Many factors taken into account, an expression may fully accord to the constructional schema or have a certain conflict with it. CG calls the former situation as an elaboration of the schema and the latter as an extension.

In the present study, the disyllabic compound constructions are analyzed within the framework of CG. The components' relation, their relation to the constructions, the emergent properties of constructions, and the grammatical categories of expressions are the focus of the study.

\section{Data Extraction}

The study is based primarily on the Lancaster Corpus of Mandarin Chinese (LCMC) which was constructed by Tony McEnery and Richard Xiao in 2003. The most important reason is that this corpus has been coded with parts of speech (POS), which is seldom done in most corpora of Chinese. The coding was first done following the coding system of Chinese Academy of Sciences. Then it was checked and corrected manually by the builder of the corpus, a native speaker and linguist. So the coding is $98 \%$ correct (Xu [35]) and is reliable for the present study.

The text categories in the LCMC corpus cover press, religion, popular lore to biographies, essays, miscellaneous, and to fiction and humor. The material is Mandarin Chinese including texts published in Mainland China, samples from the Internet, and newswire texts from the library and from Xinhua News Agency (excerpted from the PH Corpus). Considering the resources of the texts, the wide coverage of texts and the background of the researchers, we believe that this corpus can be used to extract Mandarin adjectives.

Totally 2483 adjectives are extracted from LCMC. Among them 319 are mono-syllabic adjectives. Those that are possible to be combined with their antonyms (if they have) and form disyllabic compounds are sorted out. Then the compounds are further checked in LCMC and CCL 
(Center for Chinese Linguistics PKU) corpus to guarantee that they are actually used instead of being created. CCL corpus was updated in 2009 and is relatively new and rich with instances, in spite of not being coded with POS. It also covers a wide range of registers and genres, such as news reportage, literature, fiction, drama, practical writing, and biography and so on. Some compounds that are lacking in LCMC do exist in CCL corpus and even constitute a big proportion. This phenomenon may be due to the researchers' view on whether the antonymous adjectives co-occurring in one disyllabic compound can be regarded as a unit or not. In all, 51 disyllabic compounds are extracted. At the phase of usage-based exploration, CCL corpus is used to extract the actual usages of antonymous adjectives co-occurring in disyllabic compounds.

Table 1. Disyllabic compounds composed of antonymous adjectives in Mandarin

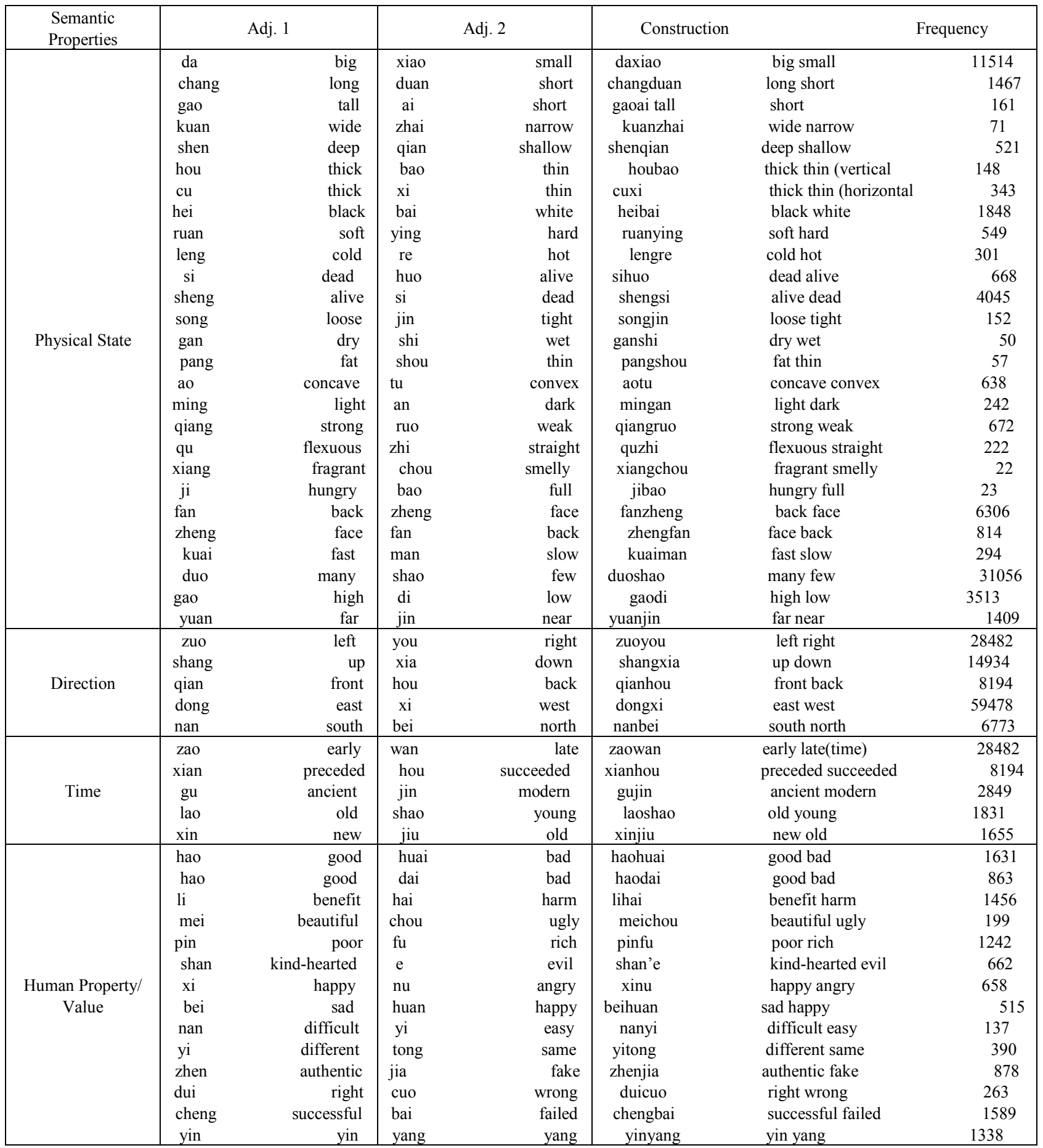




\section{The General Characteristics of the Phenomenon}

Before going further to explore the cognitive rationality of the linguistic phenomenon, we will present the general characteristics of it, including the semantic properties of component adjectives, the ordering of components in the compounds, grammatical categories and semantics of compounds.

\subsection{Semantic Properties of Component Adjectives}

The component adjectives in the 51 disyllabic compounds present the following semantic properties: they are descriptions of state instead of quality of things. The states are of both concreteness and evaluation, specifically including physical state, direction, time and property/evaluation. Besides, the component adjectives show the feature of gradability and involve scales. The component adjectives and disyllabic compounds with their usage frequencies are presented by Table 1 . The statistics are obtained from CCL corpus.

\subsubsection{State Instead of Quality}

Adjectives denote properties of things. Most of these properties can be related to a scale (Dixon [7]; Murphy [27), and represent a state on the scale. For example, 'hot water' indicates that the water is in a state of being hot. This state is on a temperature scale. Some other properties are related to what a thing is - the quality of it. For example, 'the desk is wooden' indicates that the desk is made of wood. This adjective conveys the information that the desk is made of wood instead glass or steel. So it can be seen that only adjectives related to states may have their antonyms while those related to the qualities do not have antonyms.

When we look at the compounds in Table 1, we find all of them are composed of adjectives denoting states. In other words, only adjectives denoting states can co-occur with their antonyms in disyllabic compounds.

\subsubsection{Gradability and Scale}

The most fundamental logical distinction of the antonym pairs is gradability (e.g. Lyons [21]; Cruse [2]). Paradis [30] categorizes the gradable adjectives into three: scalar adjectives, extreme adjectives and limit adjectives. The antonymous adjectives are on the same semantic scale but represent contrasting states. As for the scalar adjective pairs, there is no clear-cut boundary between the two states. Instead, both states are gradable in both directions of the semantic scale, hence a certain overlapping area on the scale. In this area, a state may be described by either component adjective. In other words, they leave "semantic space" for each other. For example, 长 chang 'long' and 短 duan 'short' are on the scale of dimension. We can describe a rope of two meters as long when it is compared with a rope of one meter. We can also describe the same rope as short when it is compared with a rope of three meters. Therefore, there must be a standard.
The limit adjective pairs divide the scale into two parts without space for any intermediate state. Anything can be in either state. For example, a rat is alive. This means that it is not dead. The extreme adjectives represent two extreme ends of the semantic scale and indicate extreme states. For example, 完美 wanmei 'perfect' means 'extremely good'. The non-gradable adjectives are not related to gradability at all (Paradis [28]), such as 'daily newspaper' and 'classical ballet'. These adjectives cannot be put on a semantic scale, thus it is impossible to find their contrast on a scale. Therefore, they cannot form disyllabic compounds.

In our data, it can be found that both scalar and limit adjectives appear in the compounds, such as 大小daxiao, literally big-small, 多少 duoshao, literally many-few, 生死 shengsi, literally alive-dead, 真假 zhenjia, literally authentic-fake, 对错 duicuo, literally right-wrong and so on. It is also found that compounds composed of scalar adjectives and those composed of limit adjectives constitute quite different proportions, which may be attributed to the fact that there are less limit adjectives than scalar ones.

\subsubsection{Concrete Properties and Evaluative Properties}

Seven classes of adjectives in English were distinguished in Dixon [6]. The semantic properties include dimension, physical properties, colors, human properties, age, value and speed. Age, dimension, value and color are cross-linguistic properties of adjectives even in languages which have few adjectives. As is shown in Table 1, the semantic properties of Mandarin adjectives cover all the aspects in Dixon [6]. Only by the raw usage frequencies of the compounds, it is hard to identify which type of property of an individual adjective may contribute more to its co-occurrence with its antonym in a disyllabic compound, since even adjectives of the same property type show significant variations in the usage frequencies of compounds that they form.

However, we do find that antonymous adjectives denoting concrete properties contrast sharply with those denoting evaluative properties in their usage tendencies of co-occurring in compounds. The former category includes physical state, direction, and time adjectives. The latter category includes human properties and value adjectives. It is found that about $71 \%$ of the component adjectives denote concrete properties, such as 高 $g a o$ 'tall', 矮 $a i$ 'short', 饥 $j i$ 'hungry' and 饱 bao 'full', only $29 \%$ denoting evaluative properties, such as 好 hao 'good', 坏 huai 'bad', 喜 $x i$ 'happy', and 怒 $n u$ 'angry'.

\subsection{Ordering of Adjectives in Compounds}

The antonymous adjectives in disyllabic compounds are found to be in a fixed order. For example, it is grammatical to say 高矮 gaoai, literally tall-short, 'height', but not to say 矮高 aigao. A closer look indicates that for the adjectives denoting concrete properties, the unmarked adjective is usually ahead of the marked one, such as 大小 daxiao, literally big-small, 'size', 远近 yuanjin, literally far-near, 'distance', 长短 changduan, literally long-short, 'length', 
老少laoshao, literally old-young, 'the old and the young', 古今 gujin, literally ancient-nowadays, 'from the ancient to nowadays'. For the adjectives denoting evaluative properties, the adjective at the positive end is usually ahead of that at the negative end, such as 喜怒 xinu, literally happy-angry, 'mood', 好坏 haohuai, literally good-bad, 'good or bad', 善 恶 shan'e, literally kind-hearted-evil, 'nature of a person', 成败 chengbai, literally successful-failed, 'success or failure'. However, it is not always the case. Exceptions do exist, for example, 悲欢 beihuan, literally sad-happy, 'sadness and happiness' is ordered by the negative adjective ahead of positive one. In addition, a pair of antonymous adjectives in our data is exceptional. Both 正反 zhengfan, literally face-back, 'face side and back side' and 反正 fanzheng, literally back-face, 'in any case' are grammatical. Their different orders have a consequence in their semantics and grammatical categories.

\subsection{Semantics and Grammatical Categories of Compounds}

That the components are adjectives does not mean that the compounds are adjectives. A compound, as a construction, has its own semantic variations and grammatical categories. For example,

(5). 分布于世界各地的大小河流，自古以来就是 人类生息繁衍的主要活动场所。

Fenbu yu shijie gedi de daxiao heliu, zigu yilai jiushi renlei shengxi fanyan de zhuyao huodong changsuo

Distribute world everywhere big small river ancient times since is human beings multiply main activity place

The rivers, big or small, distributed around the world, represent the places where human beings have multiplies.

(6). 这幅图中有三个大小不同的正方形。

Zhe fu tu zhong you san ge daxiao butong de zhengfangxing

This picture have three CL. big small different square

There are three squares of different sizes in this picture.

In (5), 大小河流 can be interpreted as 'big rivers and small rivers', 大 and 小 still maintain their part of speech as adjectives and describe the noun 'river'. The semantics of the compound is the conjunction of the meanings of two component adjectives. In (6), 大小不同 conveys 'different sizes'. The compound denotes the generalization or abstraction of properties denoted by the component adjectives. 大小 functions as a noun meaning 'size'. Look at the following examples:

(7), 朱晖高低不肯。
Zhuhui gaodi buken

Zhuhui high low not agree

Zhuhui did not agree in any case.

(8). 某些人左右不了中美关系正常发展的趋势。

Mouxieren zuo you bu liao zhong mei guanxi zhengchang fazhan de qushi

Some people left right not Asp. China America normal development tendency

Some people cannot hinder back the development of the normal relationship between China and America.

高低不肯 gaodi buken is irrelative to the height. 高低 gaodi indicates the degree of the VP 不肯 and can be understood as 'in any case'. It functions as an adverb. 左右 zuoyou in (8) even functions as a verb which has its subject and object. It means 'control' which has nothing to do with the position of being left or right.

The data in corpus show that the disyllabic compounds composed of antonymous adjectives may function as adjectives, nouns, verbs and adverbs. The semantics of each compound can be related to the component adjectives and can also extend from the components. The background cognitive rationality is worthy of being explored, which is the focus of next section.

\section{Cognitive Explanation}

The above section makes clear several aspects related to the phenomenon of antonymous adjectives co-occurring in disyllabic compounds. These aspects are supposed to be accounted for. A top-down approach will be adopted, centering on the analysis of the semantics and grammatical behavior of compounds, and how components contribute to the compounds.

\subsection{Semantic Type I-Conjunction}

An adjective, having only trajector in a relational expression, 'profiles the configurational assessments' (Langacker [19]:114). The trajector can be usually situated on a scale. The adjective specifies the property and evokes the scale at the same time. From the conceptual perspective, the property represents the content domain while the scale represents the schematic domain. Both the content and schematic domains are conceptual and reflect our perception of the world (Paradis [30]). However, the domains themselves cannot independently determine the semantics of adjectives, the ranking of the prominence of the conceptual domains has an effect (Langacker [18]). Let us take example (5) to illustrate this, repeated here as example (9).

(9). 分布于世界各地的大小河流, 自古以来就是 人类生息繁衍的主要活动场所。

Fenbu yu shijie gedi de daxiao heliu, zigu yilai jiushi 
renlei shengxi fanyan de zhuyao huodong changsuo

Distribute world everywhere big small river ancient times since is human beings multiply main activity place

The big and small rivers, distributed around the world, represent the place where human beings have multiplies.

In this sentence, the construction 大小 daxiao literally big-small, is attributive and describes the feature of the NP 河流 heliu 'river'. '大小河流' is understood as 'big rivers' and 'small rivers'. It cannot be denied that the economy of language is one motivation for their co-occurrence, but without the shared content and scale that they are both conceptualized by, the economy cannot be realized. In (9), the rivers are categorized by the parameter-the scale of 'size'. Each member in the category of river is bound to a position on the scale. The co-occurrence of 'big' and 'small', with the relation represented by 'and', activates the prominence of content domains of all the members on the scale. This is classified as the Semantics Type I-Conjunction. One consequence brought forth by the co-occurrence is that the NPs in this construction always indicate a collection of things, not individuating a particular member, as also observed in the corpus. The cognitive process is shown in Figure 1. The left rectangle represents the constructional schema of the disyllabic compound composed of two antonymous adjectives. The right big rectangle represents the instantiation of the construction. The dark and small line on the scale represents the prominence of members. The dotted lines represent the mapping from the noun category to the scale. The arrow in the middle of two rectangles represents the instantiation. The two meeting arrows represent conceptual blending.

Antonymous adjectives of Semantics Type I have their content domains in the foreground and the schematic domains at the background, mapped from which, the disyllabic compounds inherit the grammatical categories of the components and function as adjectives. Besides, in this case, the semantics of components contribute to the disyllabic compounds in the way of conjunction of their prototypical meanings. The following are more examples of adjectives of other property types.

\section{(10). 他的书法,左右手都能写出刚劲有力的字体。}

Ta de shufa, zuoyou shou dou neng xie chu gangjin youli de ziti

His handwriting, left right hand all can write vigorous powerful style of calligraphy

His handwriting is so good that he can write vigorous and powerful characters with his right or left hand.

(11). 干热风、早晚霜、冰雹等自然灾害减轻。

Gan re feng, zao wan shuang, bingbao deng ziran zaihai jianqing

Dry hot wind, morning evening frost, hail etc natural disaster decrease

The natural disaster like dry and hot wind, morning and evening frost, and hail, has decreased.

(12). 我们必须看到,好坏因素都存在。

Women bixu kandao, haohuai yinsu dou cunzai

We must see good bad factors all exist

We must know that both good and bad factors exist.

The corpus investigation shows that not all the antonymous adjectives in Table 1 can be used for Semantic Type I, but Semantic Type I can occur to each property type of adjectives.

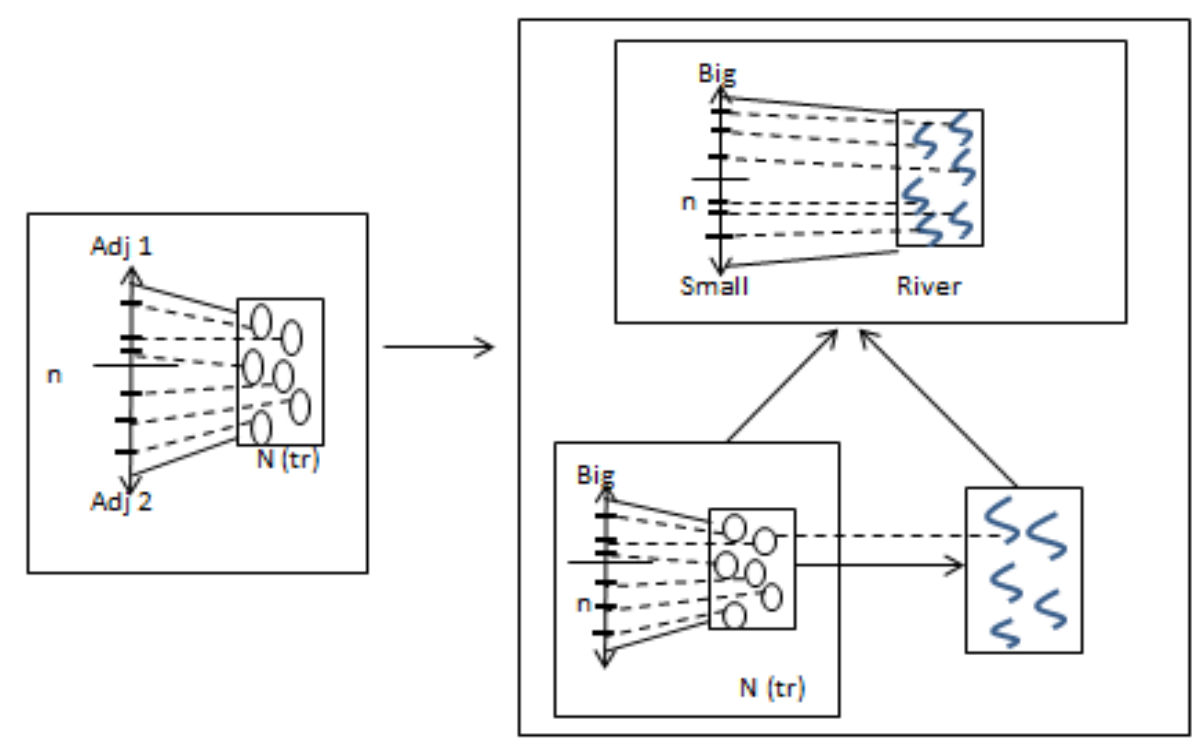

(大小河流 daxiaoheliu 'big and small rivers' as an example)

Figure 1. Semantic Type I-Conjunction 


\subsection{Semantic Type II --Generalization}

When antonymous adjectives co-occur, content domains do not always stay in the foreground. The disyllabic compound construction is itself a factor which may have a coercive effect on its components. With the coercion, the schematic domains may take the place of the foreground and the content domain is de-profiled. This cognitive process has the semantics as well as grammatical consequences. For example,

(13). 无论高矮、胖瘦, 谁都可以穿上合体的西装。

Wulun gaoai, pangshou, shui dou keyi chuanshang heti de xizhuang

Whatever tall short, fat thin, who all may wear suitable suits

Whatever are the shapes or sizes, anyone can wear suitable suits.

(14). 王海蓉唐文生在毛泽东晚年经常陪伴其左 右。

Wang Hairong Tang Wensheng zai Mao Zedong wannian jingchang peiban qi zuoyou

Wang Hairong Tang Wensheng in Mao Zedong later years accompany his side

Wang Hairong and Tang Wensheng often accompanied Mao Zedong by his side in his later years.

(15). 连环画是老少都可以读的书。

Lianhuanhua shi laoshao dou keyi du de shu

Comic books are old yound all may read books

Comic books are appropriate for people of all ages.

(16). 理解按其难易可以分为直接理解和间接理 解两种。

Lijie an qi nanyi keyi fenwei zhijie lijie he jianjie lijie liangzhong

Understanding according to its difficult easy may divide direct understanding and indirect understanding

Understanding can be divided into direct and indirect ones according to the degree of the difficulty.

It can be seen that the disyllabic compound constructions, like 高矮 gaoai literally tall-short, height of a person, 左右 zиoyou literally left-right, one's side, 老少 laoshao literally old-young, people of all ages, 难易 nanyi literally easy-difficult, degree of difficulty, do not inherit the grammatical categories of the components. They, however, function as nouns in these examples. As for the semantics, the properties of individuals are not the focus, as is the case for Semantics Type I. The generalization of individual properties, the shared scale of the antonym pair, is prominent. The scale of 高矮 is the height, 左右 the direction, 老少 the age, and 难易 the difficulty.

A trajector can be mapped onto either end of the scale if its content domain is prominent. However, when both ends are linguistically represented and there is only one trajector, the content domain must be de-profiled to avoid conflicts in semantics and make the cognitive process feasible. For example, a river cannot be both big and small as far as one construer or one standard is concerned. In this case, the schematic domain, the whole scale, profiles. It can be construed as a region, whether bounded or unbounded, thus can be nominalized. This nominalized scale is understood as one profiled aspect of the noun, shown as Figure 2, with (13) as an example. The bottom left rectangle indicates that the shared scale of the adjectives is prominent and conceptualized as a bounded region in the constructional schema. The bottom right rectangle represents a noun schema with one aspect profiled. The dotted lines between them represent correspondences. The top rectangle represents the schema of the compound construction with the semantics of 'generalization'.

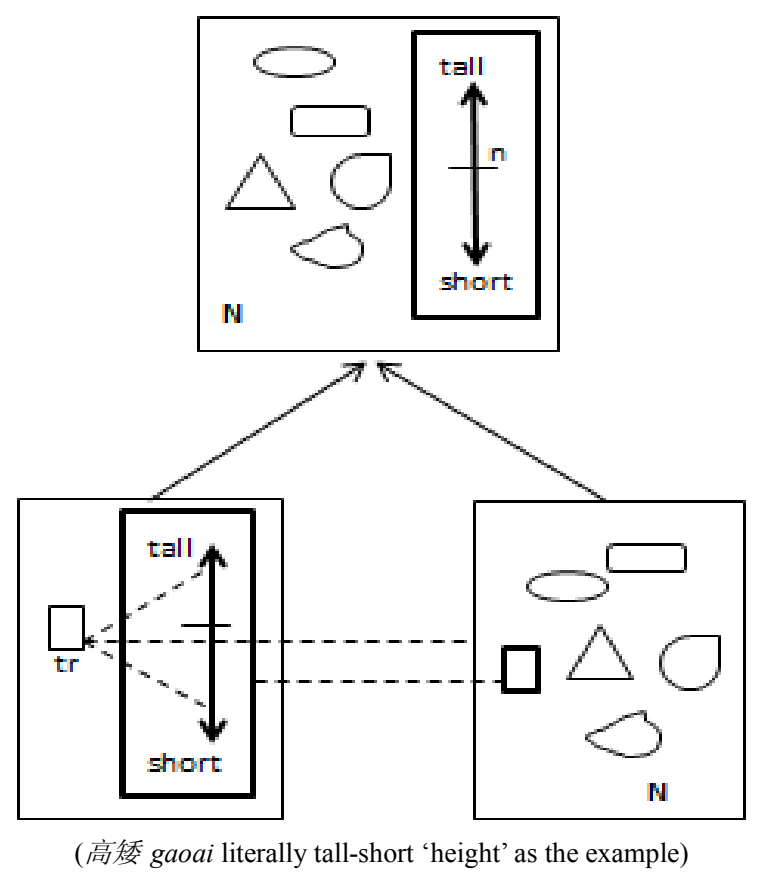

Figure 2. Semantic Type II-Generalization

The corpus shows that all adjectives of each property type can co-occur to function as nouns and convey the semantics of the scale shared by both of them. This use of constructions accounts for the largest proportion in the corpus. This reflects the usage tendency of the construction, as well as the cognitive nature of antonymous adjectives. They contrast in semantics, but they also tend to attract each other and co-occur to stimulate the shared and general properties to a great extent.

On the basis of the concrete uses, the construction functioning as nouns can also be used metaphorically and metonymically. For example, 
(17). a 它的体色随季节冷热的变化而变化。

Ta de tise sui jijie lengre de bianhua er bianhua

Its skin color with season cold hot change but change

The color of its skin changes with the seasons.

$\mathrm{b}$ 市场没有绝对的冷热.

Shichang meiyou juedui de lengre

Market have not absolute cold hot

There is no absolutely extreme state of the market.

(18). a 古今中外,一切正直的人都有一种共同的优 良品质。

Gujin zhongwai, yiqie zhengzhi de ren dou you yizhong gongtong de youliang pinzhi

Ancient modern home abroad, all honest people all have a kind of same excellent quality

All the honest people, from the ancient to the modern times, home and abroad, have the same excellent quality.

\section{$\mathrm{b}$ 词科考试要求考生需博览古今。}

Cike kaoshi yaoqiu kaosheng xu bolan gujin

Lexicon subject examinations require examinees must read extensively ancient modern

Lexicon examinations require the examinees to read extensively works of ancient and modern times.

冷热 lengre, literally cold-hot, in (17a) indicates the temperature, while in example (17b), 冷热 lengre is used metaphorically to mean the extreme states of the market. In (18a), 古今 gujin, literally ancient and modern, means the ancient and the modern times which is concretely related to the dimension of time, while 古今 gujin in (18b), in the context, metonymically refers to the works of ancient and modern times. The metaphorical and metonymical uses of the disyllabic compound construction constitute another piece of evidence of the conventionality of the noun uses of this construction, and explain the high usage frequency of Semantic Type II of the construction.

\subsection{Semantic Type III- 'In Any Case'}

The changes of the profile of the conceptual content and the construal perspective have more grammatical consequences. Besides adjectives and nouns, the disyllabic compound constructions also function as adverbs. For example,

(19). 咱们左右都没活路了。

Zanmen zuoyou dou mei huolu le

We left right all no living ways Asp.

We cannot survive in any case.

(20). 通讯员高低不答应,挟着被子就走了。
Tongxunyuan gaodi bu daying, jia zhe beizi jiu zou Asp.

Correspondent high low not agree carry under an arm quilt then leave Asp.

The correspondent would not agree in any case and then left with the quilt under the arm.

(21).他死活都不肯做这种事。

Ta sihuo dou buken zuo zhe zhong shi

He alive dead not willing do this kind thing

He would never do this kind of thing in any case.

(22). 去年的日子好歹也过去了,今年呢?

Qunian de rizi haodai ye guoqu le, jinnian ne

Last year days good bad also pass Asp. This year question word

The days of last year have passed in any way. How about this year?

In cognitive grammar, adverbs, like adjectives, only have one focal participant in profiling a non-processual relation. The trajectory of an adjective is a noun, while that of an adverb is a relation. The relation is usually designated by action verbs. This is a process of how certain aspects of the action are prominent and linguistically represented. As illustrated by Example (19)-(22), the extent of actions is made explicit by the disyllabic compound construction. The cognitive process is as the following.

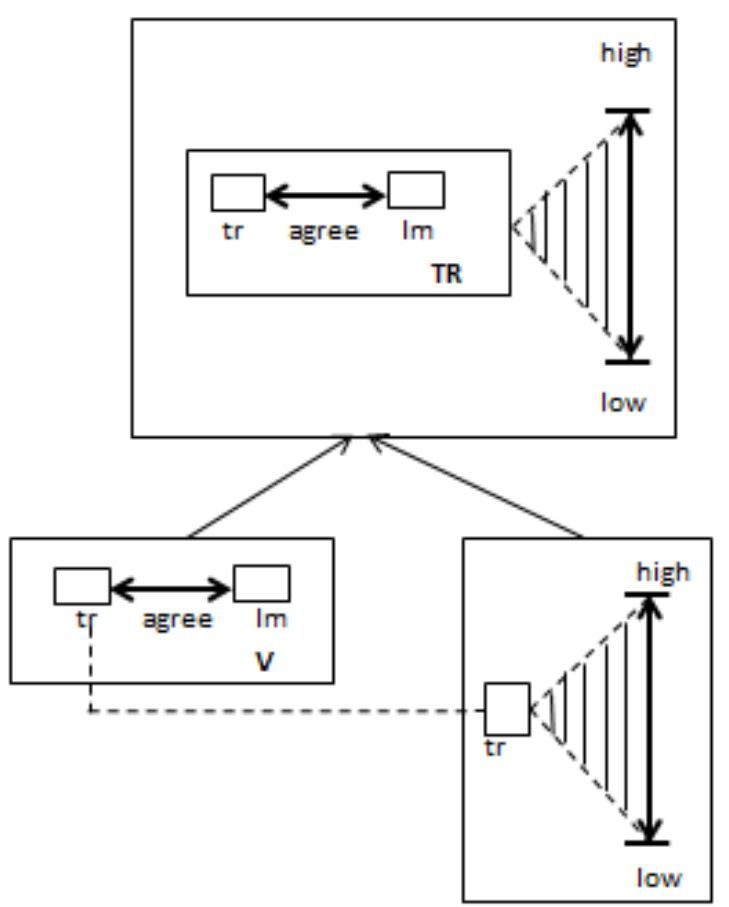

Figure 3. Semantic Type III-Discourse particle (in any case)

In this case, the construction plays its coercive effect under which the content domains of adjectives are de-profiled and schematic domains serve their functions in 
the foreground. In other words, the scale evoked by the antonym pair is prominent. The trajector is related to the scale in a static state. When the trajector interacts with the physical world, its dynamic aspect becomes prominent and an action occurs. With the occurrence of the action, the action becomes the trajector and is mapped onto the scale. This is the conceptual foundation of adverbs. In this relation, in whatever way the action occurs, it can always be mapped onto the scale. As discussed above, the adjectives in the construction include scalar and limit ones. For the scalar adjectives, an extreme can be imposed on the scale by construal. Therefore, the antonymous adjectives in this construction are coerced to indicate extreme states. When extreme states emerge at both ends, the action cannot occur beyond the scope of the scale. So the consequent meaning is that the action will occur in any case. For the limit adjectives like 死 $s i$ 'dead' and 活 huo 'alive', only two states are involved and there are no variation related to each state. Their co-occurrence serves the same function as the scalar adjectives in indicating "in any case". The whole cognitive process is shown in Figure 3, taking (20) as an example. The bottom left rectangle is the schema of verb. The right one indicates a construal of boundary is imposed on the scale and the scale is prominent. The top rectangle represents the schema of the compound construction indicating the action becomes the trajector and is mapped onto the scale.

Another problem related to this use of the construction is the boundedness. It is found that the actions in the above contexts are all bounded conceptually. This can be accounted for from the perspective of the correspondence of boundedness between the action verb and the adverb. Boundedness, in semantics, has been studied a lot (Dahl [3]; Langacker [18]; Talmy [34]; Jackendoff [13]; Depraetere [5]; Shen [33]; Paradis [30]), but the correspondence of boundedness between different grammatical categories is not so much studied, one being Pardis [30]'s research on the boundedness of adjectives and degree adverbs. The disyllabic compound construction indicating the extremeness of inclusion represents a bounded region, which has bi-directional effects on the action. The action should be a perfective one representing a bounded region on the temporal axis. Only the conceptual correspondence between the boundedness of actions and degrees can guarantee the grammatical appropriateness of the linguistic expression.

The antonymous adjectives co-occurring in the construction of Semantic Type III account for a small proportion. This usage is conventionalized and usually used in speech. Conventionalization is possibly one reason. It may be the case that more antonymous adjectives are invited to this usage by pragmatic strengthening in the future.

\subsection{Semantic Type IV - 'Control'}

The last type of semantics that are related to the disyllabic compound construction is quite specific-'control'. Only one pair of antonymous adjectives is found to be used as a verb meaning 'control'. That is 左右 zuoyou literally left-right. Even though this is not a common phenomenon, we still include it in the discussion, because this pair is also found to function as adjectives, nouns, and adverbs, and its use as a verb must be relevant to other uses from the cognitive perspective. Besides, functioning as a verb represents a usage tendency of the disyllabic compound construction. So it is necessary to explore the cognitive mechanism of this usage. For example,

\section{(23). 他作为一个军团的领导无力左右局势。}

Ta zuowei yige juntuan de lingdao wuli zuoyou jushi

$\mathrm{He}$ as a legion leader no power left right situation

As a leader of the legion, he has no way to control the whole situation.

(24). 七个工业大国左右不了全球的经济事务。

Qi ge gongye daguo zuoyou bu liao quanqiu de jingji shiwu

Seven industrial country left right not Asp. Global economic affairs

The seven industrial countries cannot control the global economic affairs.

左 zuo 'left' and 右 you 'right' are direction adjectives and can be positioned on a directional scale. This pair of adjectives is special in that the ego is usually involved when they are used. A left object and a right object are grounded within the view scope of the ego. When the ego changes a perspective, the expression will also be changed. What is more important, the scale of left and right cannot extend without any limit. There is a scope prediction in relation to the ego. Beyond the scope, things are too distant from the ego to be expressed by 'left' or 'right'. So a dominion is formed by the three points - Ego, the most left location and the most right location, shown as Figure 4. The circle represents the ego which may be implicit or explicit. Dark spot 1 represents the most left location within the dominion and dark spot 2 the most right one. All the dark points represent the locations that fall within the dominion which is limited to the area of the triangle. The middle dotted line is the reference point adopted by the ego to refer to the left area and the right area.

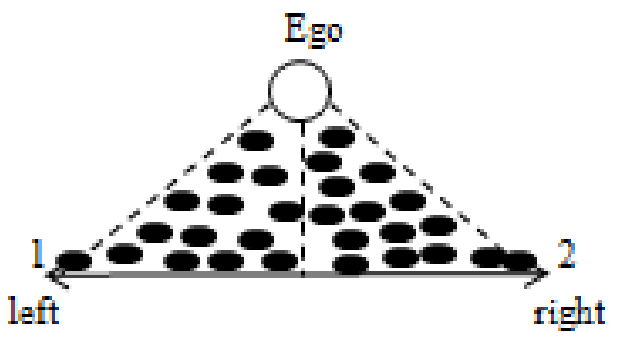

Figure 4. The dominion of 'left' and 'right'

From another perspective, the things or locations within the dominion are within the control of the ego. The ego can interact with each of the things within the dominion. Once the relation occurs, an action is evoked. 
The interaction may occur between the ego and the thing at each location, but not beyond the dominion. In other words, the interaction is always in the control of the ego. The control dominion is limited to the area set by the left and right ends of the scale and the ego. Therefore, the relation is related to 'left' and 'right'. This process is illustrated by Figure 5, taking instance (23) as an example. The bottom left rectangle represents the dominion of the ego. The right one represents the interaction between the ego and one member in the dominion. The top rectangle indicates that the interaction can only occur within the dominion.

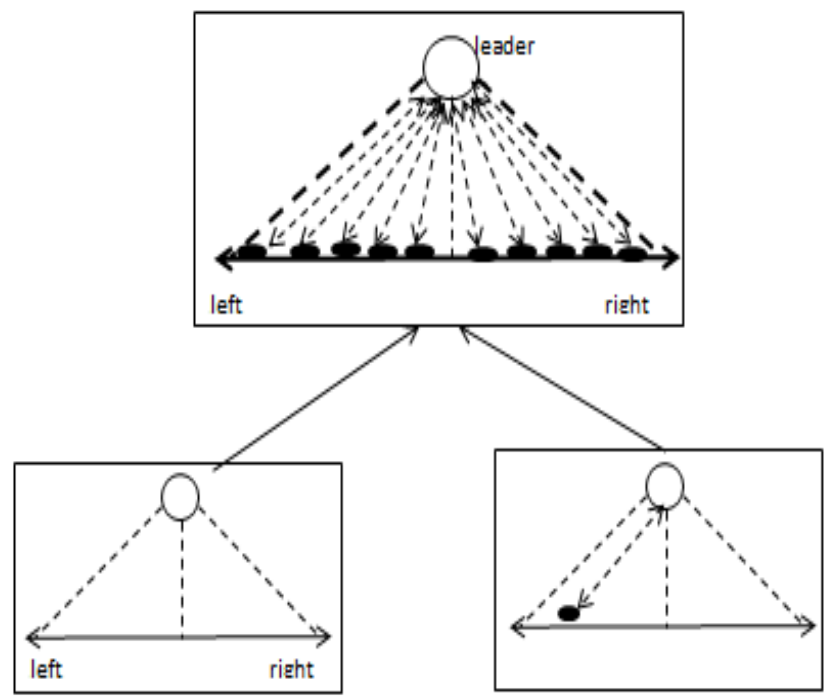

Figure 5. Dominion of controlling set by 'left' and 'right'

The antonymous adjectives co-occur linguistically which indicates the prominence of two extreme positions. They can then function as the reference point to refer to the control dominion that the ego can dominate in performing a certain action. Then the dominion stands out to refer to the action of controlling. Through the EXTREME POSITION FOR CONTROLING DOMINION FOR ACTION OF
CONTROLING metonymic chain, the co-occurrence of antonymous adjectives 左 zuo 'left' and 右 you 'right' are related to time and used as a verb meaning 'control'. Figure 6 shows the cognitive mechanism.

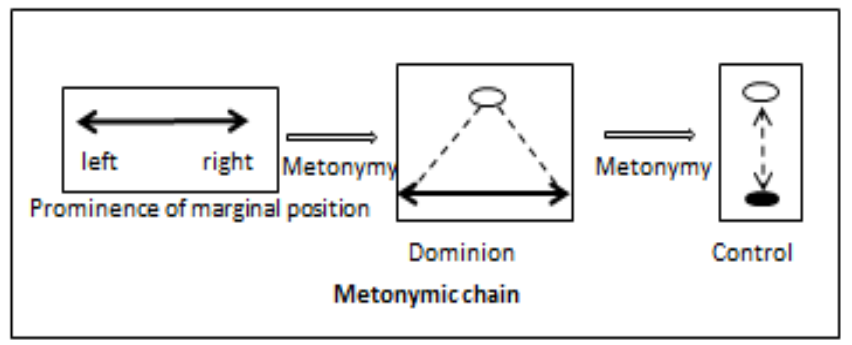

Figure 6. Semantic Type IV_-'Control'

\subsection{The network}

A same syntax form can be related to different semantics. The semantic (in-) compatibility between lexical items and construction meaning has attracted attention a lot (Ziegeler [38]; Langacker [20]). The above analyses indicate how the antonymous adjectives perform in the disyllabic compound construction to fulfill different semantics in different grammatical contexts. The disyllabic construction, as a higher-level conceptual pattern, incorporate lower-level patterns like antonymous adjectives, according to the general principle of conceptual integration (Ruiz de Mendoza Ibáñez [31]). The more concrete structure tends to be adapted into more abstract pattern if there is any conflict (Ruiz de Mendoza Ibáñez \& Díez Velasco [32]). In the present study, the antonymous adjectives are incorporated into the disyllabic constructions, and the constructions are incorporated into more general constructions. The grammatical constructions thus have a hierarchical effect on expressions from the general to the specific. The following figure shows the bi-directional relations between component adjectives and constructions.

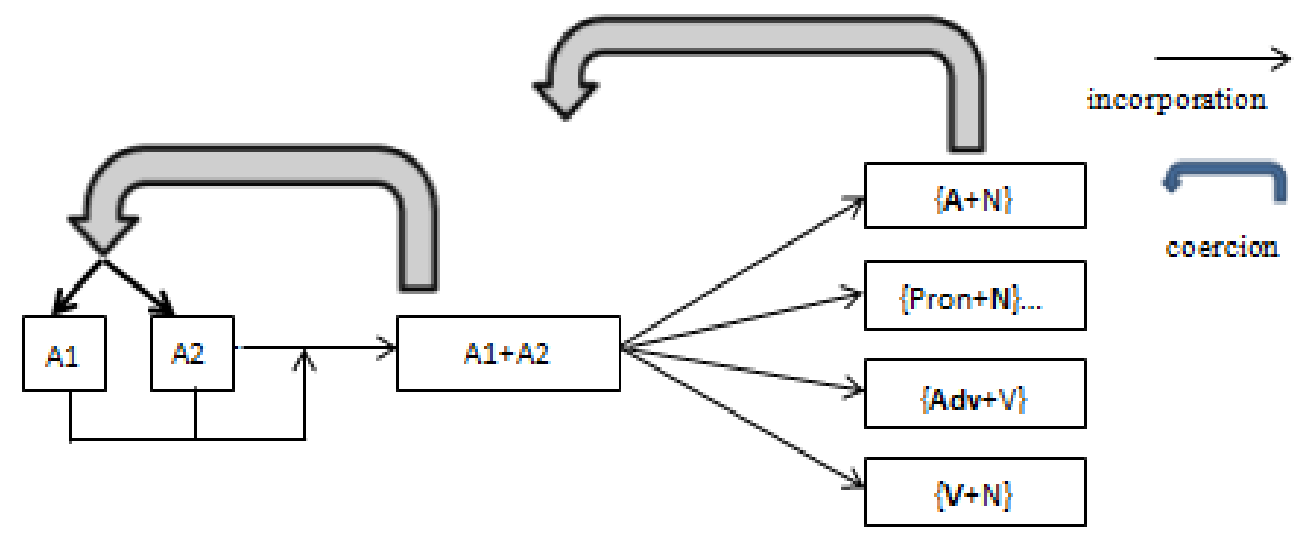

Figure 7. Bi-directional relations between component adjectives and constructions 
Grammar is by and large motivated by semantics (Goldberg [10]). Constrained by the economy of language, one construction may code similar or relative conceptual contents, thus forming polysemy of the construction (Goldberg [9]). To construct the semantic network of the construction, it is crucial to explore the cognitive motivation for the semantic extension.

The most direct semantic consequence of the co-occurrence of the antonymous adjectives in compounds should be the composition of componential meanings. In other words, the construction meaning is completely predictable from the componential meanings. The content domain of the construction is constructed by the content domains of components. That is the first type of semantics, the relation of conjunction.

In the Semantic type I, both the properties represented by the antonymous adjectives are prominent. If either property is construed as a domain, they share a matrix domain which is the scale that antonymous adjectives invoke. The domain is featured by the shared and general properties of members in it. According to the principle of metonymy, sub-domains may serve as the reference point to access the matrix domain, thus the INDIVIDUAL PROPERTY FOR GENERAL PROPERTY metonymy. This is a process of domain expansion, shown as Figure 8.

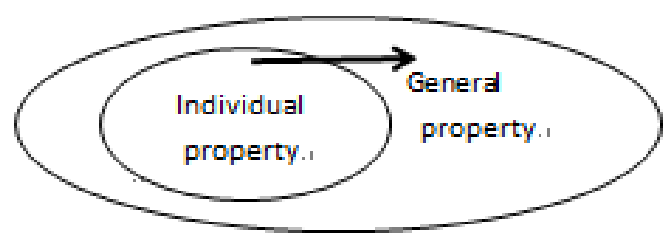

Figure 8. The Metonymic process from Semantic Type I to Semantic Type II

The general property can be nominalized with a different construal. When the nominalized property is related to a thing, it becomes one facet of the thing. This cognitive process of metonymy results in the Semantic Type II.

The metonymic process does not stop. When a boundary construal is imposed on the scale, the matrix domain of the scale can further serve as a reference point to activate two special sub-domains - the two boundary members of the scale. The boundary members represent extreme states which further help to access an extent of extremeness (linguistically represented by 'in any case'). Through the metonymic chain GENERAL PROPERY FOR BOUNDARY MEMBER FOR EXTENT OF EXTREMENESS. This is how Semantic Type III extends from Semantic Type II, shown as Figure 9. The process involves the reduction of cognitive domain.
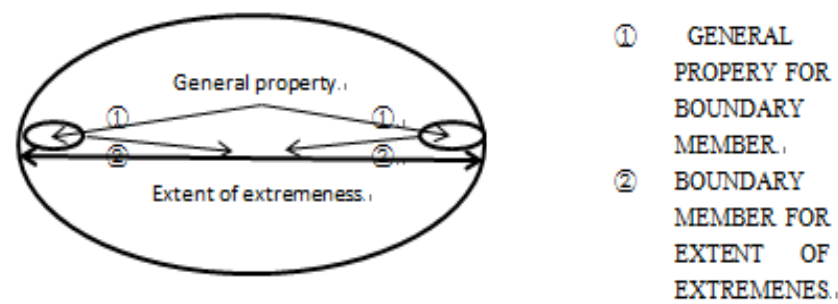

Figure 9. The Metonymic process from Semantic Type II to Semantic Type III

As for Semantic Type IV, the meaning of 'control' is closely tied to Semantic Type III 'in any case'. Even though this meaning is only constrained to a particular antonymous adjective 左右 zuoyou literally left-right, the cognitive motivation can still be potentially generalized. In analyzing Semantic Type III, an extent of a stretching scale is activated. The extent can itself serve as a subdomain to activate a dominion of controlling which further activates the action frame of controlling. This involves double expansions of cognitive domains, shown as Figure 10.

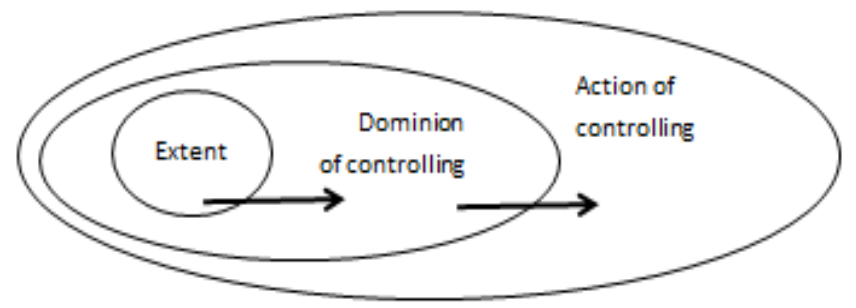

Figure 10. The Metonymic process from Semantic Type II to Semantic Type III 


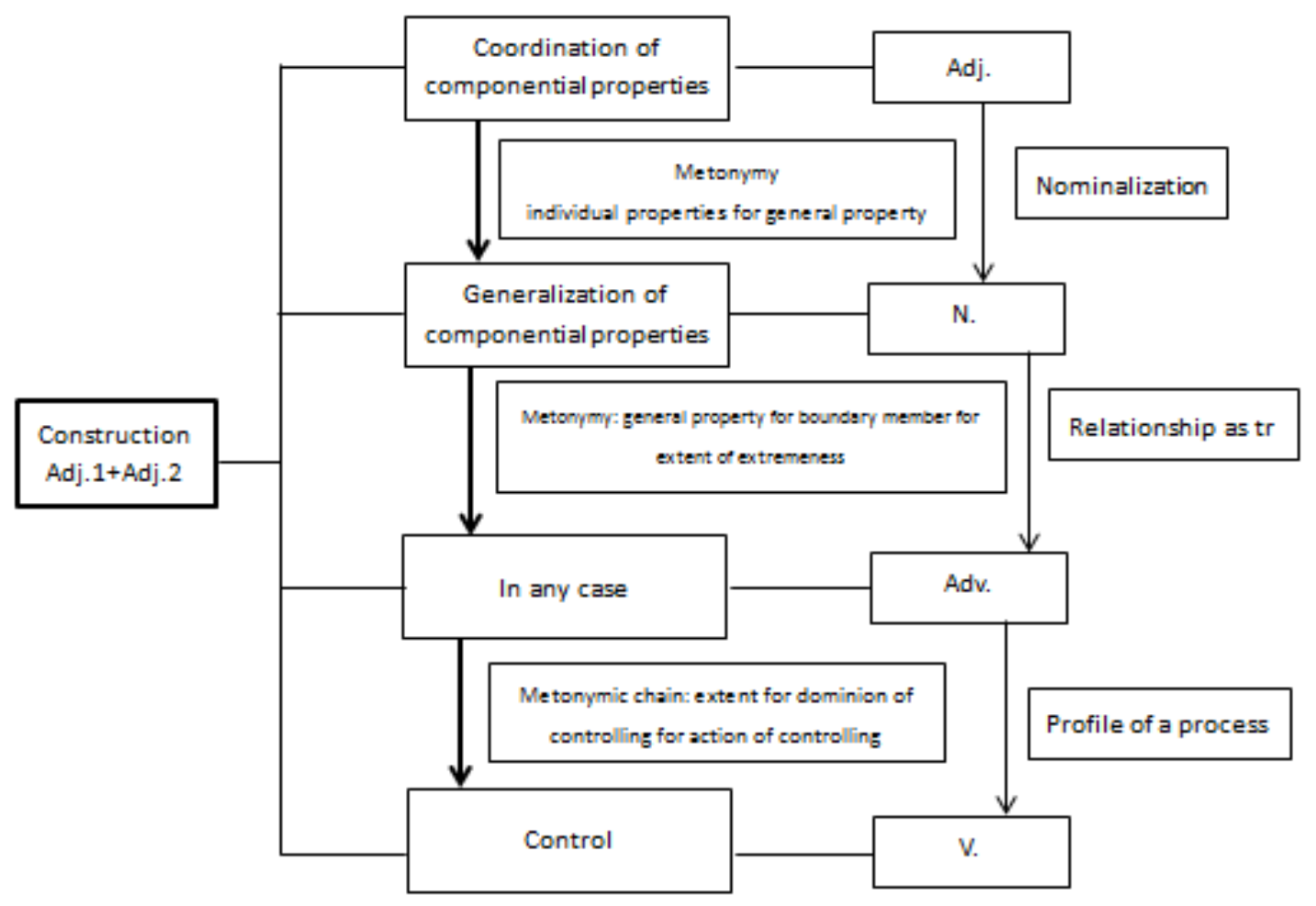

Figure 11. Semantic extension and change of grammatical categories of the disyllabic compound construction

The prototypical sense of the construction is the most highly predictable one. By the cognitive mechanism of metonymy, this sense has been extended to other senses which are mapped onto grammar and result in different grammatical categories. The further the extended senses are from the prototypical one, the more abstract and unpredictable they are. The disyllabic compound construction, its coercive effect, with the grammatical environments, becomes more and more dominant to the semantics of the construction. The variations in both the semantics and the grammatical categories show the different profiles and construal of the same conceptual content. The whole picture of the construction is shown in Figure 11.

\section{Further Discussion}

How a limited number of forms are combined to convey rich meanings is a topic worthy of being studied in human language. The economy of language being one motivation, the cognition and background knowledge of the users are factors contributing to the interpretation of the disyllabic compound construction.

Besides the cognitive mechanism analyzed in Section 5, another important factor is the cultural aspect. This aspect is similar to 'Swedish lagom values-i.e. the valuing of moderation and compromise in all things' (Murphy et al. [28]: 2179). The doctrine of Moderation has a long history since the times of Confucius. It cannot be denied that Moderation has always been influencing all fields in China, including politics, economy, and education and so on. Language is no exception. In Chinese, many expressions reflect such a doctrine, for example, 不好也不坏, literally 'neither good nor bad', 不多不少 literally 'neither many nor few',etc. These expressions are often related to antonyms and convey a person's evaluation on something. The evaluation usually reflects the person's deep outlook of the world or life. The conventionalization of these expressions indicates the rooted Moderation in Chinese people's mind. With this background cultural knowledge, it is not difficult to understand why the co-occurrence of antonymous adjectives in a compound construction is popular as well as conventionalized in Chinese. The contrasting semantics undergo a neutralization process, as a result of which, the semantics of the construction tend to de-profile the contrasting aspects and profile the shared properties.

Another phenomenon related to this construction is the order of antonymous adjectives. Table 1 shows that all the constructions begin with the adjectives at the positive end of the scale or the unmarked adjectives except several pairs悲欢 sad-happy, 贫富 poor-rich, 死活 dead-alive, 冷热 cold-hot and 反正 back-face. In other languages, similar tendencies also exist. This phenomenon can be seen as the iconic effect of human being's cognition and psychology. People usually tend to expect the positive aspect of a two-side thing to happen. As for the exceptional pairs, they may be the result of pragmatic strengthening, cultural and social background.

It is also found in the corpus that the noun use of the construction meaning the generalization of component properties accounts for the largest proportion. For one thing, this can be due to the metaphorical and metonymical uses of nouns; for another, the co-occurrence of antonymous adjectives has its own significance-to convey richer 
meanings than the component adjectives can do. However, not all the extended senses are ascribed to most antonym pairs. Semantic type III and IV are also conventionalized but confined to a few pairs of antonyms. Many factors may be involved, such as pragmatic strengthening, abstractness of senses, the conceptual distance between the extended senses and the prototypical one, and the community using the language and so on.

\section{Conclusions}

The linguistic phenomenon of the disyllabic lexical compounds composed of two antonymous adjectives is popular in Chinese. The present study takes a cognitive perspective and mainly provides an explanation for this phenomenon. The compound, as a construction, has several meanings related to the same form. The conceptual domains (including content domain and schematic domain) related to component adjectives contribute to the construction semantics and the construction has a coercive effect on the component adjectives when different construal is adopted. The cognitive exploration of the construction reveals that 'scale' and 'boundary' are two key concepts to explain the construction. The semantics of the construction, coordination, generalization, 'in any case' and 'control' coherently connected, with the sense of coordination being the prototypical one. The prototypical sense is directly derived from the senses of components and inherits the grammatical category of the components. The other senses extend from the prototypical one motivated by the cognitive mechanism of metonymy. The grammatical categories change corresponding to the construal perspective on the same conceptual content.

However, the research is still in need of improving in the future. First, the comparison across different property types of adjectives can be studied; second, it is to be analyzed whether genre may be a factor influencing the usage of different semantic types of the compound; third, what aspects of the syntactic environment may affect the usages of compounds is also worth to be explored.

The usage of a language is a complex cognitive activity relating the mind to the world. The cognitive exploration of linguistic phenomena reveals to us more about the nature of language and mind.

\section{Acknowledgements}

This research is funded by "Excellent Young Scholars Research Fund of Shandong Normal University".

\section{REFERENCES}

[1] Charles, W. G. \& George A. M. (1989). Contexts of antonymous adjectives [J]. Applied Psycholinguistics 10:
$357-375$.

[2] Cruse, D. A. (1986). Lexical Semantics [M]. Cambridge University Press, Cambridge.

[3] Dahl, Ö. (1981). On the definition of the telic-atelic (bounded-non-bounded) distinction [A]. In Tedeshi, P. J. \& A. Zaenen (eds). Syntax and Semantics 14: Tense and aspect [C]. New York: Academic Press.

[4] Deese, J. (1965). The Structure of Associations in Language and Thought $[\mathrm{M}]$. Baltimore: Johns Hopkins University Press.

[5] Depraetere, I. (1995). On the necessity of distinguishing between (un)boundedness and (a)telicity [J]. Linguistics and Philosophy 18: 1-19.

[6] Dixon, R. M. W. (1982). Where Have All the Adjectives gone? And Other Essays in Semantics and Syntax [M]. Berlin: Mouton.

[7] Dixon, R. M. W. (2010). Basic Linguistic Theory: Vol. 2 Grammatical Topics [M]. New York: Oxford University Press.

[8] Fellbaum, C. (1995). Co-occurrence and antonymy [J]. International Journal of Lexicography 8: 281-303.

[9] Goldberg, A. E. (1995). Constructions: A construction grammar approach to argument structure. Chicago \& London: the University of Chicago Press.

[10] Goldberg, A. E. (2006). Constructions at work: The nature of generalization in language. New York: Oxford University Press.

[11] Gross, D., Ute F. \& George A. M. (1989). The organization of adjectival meanings [J]. Journal of Memory and Language 28: 92-106.

[12] Huang, S. 1998. Chinese as a Headless Language in Compounding Morphology [A]. In Packard, J.L. New Approaches to Chinese Word Formation [C]: 261-283.

[13] Jackendoff, R. (1991). Parts and boundaries [J]. Cognition 41: 9-45.

[14] Jones, S. (2002). Antonymy: a Corpus-based Approach [M]. London: Routledge.

[15] Jones, S. (2006). The discourse functions of antonymy in spoken English [J]. Text and Talk 26: 191-216.

[16] Jones, S., Murphy, M. L. (2005). Using corpora to investigate antonym acquisition [J]. International Journal of Corpus Linguistics 10: 401-422.

[17] Justeson, J. S. \& Slava M. K. (1991). Co-occurrences of antonymous adjectives and their contexts [J]. Computational Linguistics 17: 1-19.

[18] Langacker, R. W. (1987). Nouns and verbs [J]. Language 63: 53-94.

[19] Langacker, R. W. A Cognitive Grammar-A Basic Introduction [M]. New York: Oxford University Press, 2008.

[20] Langacker, R. W. 2009. Cognitive (Construction) Grammar [J]. Cognitive Linguistics 20:167-176.

[21] Lyons, J. (1977). Semantics [M]. Cambridge University Press, Cambridge. 
[22] Mettinger, A. (1994). Aspects of Semantic Opposition in English [M]. Oxford: Clarendon.

[23] Murphy, M. L. (2003). Semantic Relations and the Lexicon [M]. Cambridge: Cambridge University Press.

[24] Murphy, M. (2006). Constructions. Available at www.constructions-online.de, urn:nbn:de:0009-4-6857, ISS N $1860-2010$

[25] Murphy, M. L. (2010). Lexical Semantics [M]. Cambridge: Cambridge University Press.

[26] Murphy, M. L., Paradis, C., Willners, C. \& Jones, S. (2009). Discourse functions of antonymy: A cross-linguistic investigation [J]. Journal of Pragmatics, 41, 2159-2184.

[27] Murphy, M. L. \& Jones, S. (2008). Antonymy in childhood [J]. First Language 28: 403-430.

[28] Muehleisen, V. (1997). Antonymy and semantic range in English[D]. Northwestern University, Evanston, IL. Available at: http://www.f.waseda.jp/vicky/dissertation/index.html.

[29] Muehleisen, V. \& Isono, M. (2009). Antonymous adjectives in Japanese discourse [J]. Journal of Pragmatics 41: 2185-2203.

[30] Paradis, C. (2001). Adjectives and boundedness [J]. Cognitive Linguistics 1: 47-65.

[31] Ruiz de Mendoza I., Francisco J. (1997). Metaphor, metonymy and conceptual interaction [J]. Atlantis 19: 281-295.

[32] Ruiz de Mendoza I., Francisco J. \& Olga D. V. (2002). Patterns of conceptual interaction [A]. In René D. \& P. Ralf (eds.), Metaphor and metonymy in comparison and contrast [C]: 489-532. Berlin \& New York: Mouton de Gruyter.

[33] Shen, J. X. (1995). "Boundedness" and "Unboundedness". Chinese Language And Writing 5: 367-380.

[34] Talmy, L. (1988). The relation of grammar to cognition [A]. In Brygida, R. Topics in Cognitive Linguistics [C]. Amsterdam: Benjamins.

[35] Wang, Z. (2010). The Head of the Chinese Adjectives and ABB Reduplication. In Clemens, L. E. \& C.-M. L. Liu (eds). Proceedings of the $22^{\text {nd }}$ North American Conference on Chinese Linguistics (NACCL-22) \& the $18^{\text {th }}$ International Conference on Chinese Linguistics (IACL-18): 232-245. Cambridge: Harvard University.

[36] Willners, C. (2001). Antonyms in context [M]. Lund: Lund University.

[37] Xu, J. J. (2007) An introduction to Lancaster Corpus of Mandarin Chinese. English Education in China 3: 1-5.

[38] Ziegeler, D. (2010). Count-mass coercion, and the perspective of time and variation $[\mathrm{J}]$. Constructions and Frames 2: 33-73. 